\title{
Produção de matéria seca e proteína bruta e relação folha/colmo de genótipos de capim-elefante aos 56 dias de rebrota ${ }^{1}$
}

\section{Erico da Silva Lima ${ }^{2}$, José Fernando Coelho da Silva ${ }^{3}$, Hernán Maldonado Vásquez ${ }^{3}$, Saulo Alberto do Carmo Araújo ${ }^{4}$, Fábio Nunes Lista ${ }^{4}$, Dorival Pereira Borges da Costa ${ }^{5}$}

\footnotetext{
${ }^{1}$ Parte do trabalho de dissertação do primeiro autor, desenvolvida pelo Programa de Pós-Graduação em Produção Animal da Universidade Estadual do Norte Fluminense Darcy Ribeiro - UENF.

2 Zootecnista, M.Sc. Produção Animal da UENF-CCTA-LZNA, Av. Alberto Lamego, 2000, Horto, CEP: 28015-620, Campos dos Goytacazes, $R J$.

3 UENF-CCTA-LZNA, Pesquisador do CNPq, Av. Alberto Lamego, 2000, Horto, CEP: 28015-620, Campos dos Goytacazes, RJ.

${ }^{4}$ Zootecnista, Doutorando em Produção Animal - UENF-CCTA-LZNA, Av. Alberto Lamego, 2000, Horto, CEP: 28015-620, Campos dos Goytacazes, RJ.

5 Zootecnista, Doutorando da UNESP de Botucatu.
}

RESUMO - Doze genótipos de capim-elefante foram avaliados em um delineamento em blocos ao acaso com três repetições. A parcela experimental foi composta de quatro linhas com $3 \mathrm{~m}$ de comprimento, espaçadas a $1 \mathrm{~m}$ e adubadas com $100 \mathrm{~kg}$ de $\mathrm{P}_{2} \mathrm{O}_{5}, 100 \mathrm{~kg}$ de $\mathrm{N}, 60 \mathrm{~kg}$ de $\mathrm{K}_{2} \mathrm{O}$ e $25 \mathrm{~kg}$ de micronutrientes/ha. Os genótipos diferiram significativamente quanto à altura da planta e à produção de MS, de PB e matéria seca digestível (MSD)/ha. Os genótipos CNPGL 92-94-01, CNPGL 92-79-02, CNPGL 91-06-02, CNPGL 94-07-02, CNPGL 94-09-01, BAG 66, CNPGL 93-32-02 e cv. Cameroon apresentaram os maiores rendimentos de MS, PB e MSD e não diferiram significativamente quanto à relação folha/colmo $(\mathrm{F} / \mathrm{C})$. A análise de Cluster sugeriu o agrupamento dos genótipos de maior produção de MS, PB e MSD e dos genótipos com menores produções de MS, PB e MSD

Palavras-chave: cultivares de capim-elefante, híbridos intra-específicos, produção de matéria seca, produção de proteína bruta, relação folha/colmo

\section{Dry matter and crude protein production and leaf/stem ratio of elephantgrass genotypes, at 56 days of regrowth}

\begin{abstract}
Twelve elephant grass genotypes were evaluated in a randomized block design with three replications. Each experimental plot was formed by four lines with $3 \mathrm{~m}$ of length, spaced by $1 \mathrm{~m}$ and fertilized with $100 \mathrm{~kg}$ of $\mathrm{P}_{2} \mathrm{O}_{5}, 100 \mathrm{~kg}$ of $\mathrm{N}, 60 \mathrm{~kg}$ of $\mathrm{K}_{2} \mathrm{O}$ and $25 \mathrm{~kg}$ of micronutrients/ha. Significant differences were observed among the genotypes for forage plant height and dry matter (DM), crude protein (CP) and digestible dry matter (DDM) production/ha. The genotypes CNPGL 92-94-01, CNPGL 92-79-02, CNPGL 91-06-02, CNPGL 94-07-02, CNPGL 94-09-01, BAG 66, CNPGL 93-32-02 and cv. Cameroon presented the largest production of DM, CP, and DDM. There were no significant differences for DM concentration $(\mathrm{DM})$ and leaf/stem ratio (L/S) among the evaluated genotypes. The cluster analyses suggested a group of elephantgrass genotypes with higher DM, CP, and DDM production/ha and other with lower DM, CP, and DDM.
\end{abstract}

Key Words: dry matter yield, elephantgrass cultivars, intraspecific hybrid, leaf/stem ratio, protein yield

\section{Introdução}

No Brasil, as gramíneas têm grande importância, pois é o principal alimento dos animais de rebanhos leiteiros e de corte. Entre as diversas espécies utilizadas na alimentação de ruminantes, o capim-elefante (Pennisetum purpureum, Schum.) se destaca por ser, reconhecidamente, uma forrageira perene, de alto potencial de produção de MS e alto valor nutricional. Entretanto, é necessário que seja cultivado em condições climáticas adequadas e solo fértil, que ofereça condições para produção satisfatória.
O capim-elefante possui grande perspectiva para contribuir na melhoria da dieta animal e para o conseqüente incremento de produtividade. Portanto, pesquisas com esta espécie são importantes para o conhecimento científico, refletindo assim para o entendimento e sustentabilidade dos sistemas de produção.

As principais formas de utilização dessa forrageira são a capineira e o pastejo, utilizados recentemente e que, normalmente, não exigem a utilização de áreas tão extensas como as necessárias para outros capins propagados por sementes. Além dessas vantagens, o excedente de produção 
pode ser armazenado na forma de silagem. Justamente por ser uma espécie de alta produtividade e rapidez de crescimento, exige cuidados de manejo, pois a maturação implica diminuição de seu valor nutritivo. Por outro lado, sua utilização, tanto para pastejo direto quanto para cortes, muitas vezes ocorre em propriedades rurais localizadas em regiões com valor de terra mais elevado.

A contribuição desse volumoso na alimentação do rebanho pode variar conforme a exigência nutricional dos animais e depende do nível de intensificação da exploração leiteira, podendo chegar a $100 \%$ em sistemas intensivos, nos quais geralmente são utilizados animais de maior potencial genético para produção de leite.

A atividade pecuária na região norte-fluminense é predominantemente extensiva. As pastagens são a principal fonte de alimento para ruminantes e ocupam 238 mil hectares de pastagens plantadas, com um rebanho bovino superior a 518 mil cabeças (ANUÁRIO, 1999/2000). Assim, é importante o estudo de forrageiras que, quando melhoradas geneticamente, beneficiem toda a cadeia produtiva.

De acordo com Hanna (1994), a hibridação de cultivares de capim-elefante é a melhor alternativa para se obterem genótipos superiores. Híbridos intra-específicos de Pennisetum purpureum podem, tecnicamente, combinar a qualidade e o potencial de produção de cultivares de capim-elefante, porém, faltam informações para as condições brasileiras.

O objetivo neste trabalho foi avaliar a produção de MS, PB e MS digestível e a relação folha/colmo de genótipos de capim-elefante na região norte-fluminense.

\section{Material e Métodos}

O experimento foi conduzido durante o período de março a novembro de 2005, no campo experimental do Setor de Forragicultura e Nutrição de Ruminantes do Laboratório de Zootecnia e Nutrição Animal do Centro de Ciências e Tecnologias Agropecuárias da Universidade Estadual do Norte Fluminense Darcy Ribeiro, em Campos dos Goytacazes, a $21^{\circ} 44^{\prime} 47^{\prime \prime}$ de latitude Sul, $41^{\circ} 18^{\prime} 24^{\prime \prime}$ de longitude Oeste e $11 \mathrm{~m}$ do nível do mar, região fisiográfica do norte do estado de Rio de Janeiro. O solo na área do experimento é classificado como Latossolo Amarelo Distrófico Típico(EMBRAPA, 2006). Os resultados de análise deste solo foram: $\mathrm{pH} 5,5$; fósforo disponível (ppm) 4; potássio (ppm) 36; Ca+Mg $\left(\mathrm{meq} / 100 \mathrm{~cm}^{3}\right)$ 2,2; $\mathrm{Al}$ trocável $\left(\mathrm{meq} / 100 \mathrm{~cm}^{3}\right)$ 0,2 e matéria orgânica (\%) 1,72. A acidez do solo foi corrigida com a aplicação de 1 t/ha de calcário dolomítico PRNT 80\% (com base em $60 \%$ da saturação de bases).

Conforme o sistema de classificação de Koppen (1948), citado por Ometto (1981), o clima da região é do tipo Aw, tropical quente e úmido, com período seco no inverno e chuvoso no verão e precipitação anual em torno de $1.020 \mathrm{~mm}$. A precipitação pluviométrica (Tabela 1) durante o período experimental foi de $834,20 \mathrm{~mm}$ e a temperatura média de $22,5^{\circ} \mathrm{C}$, com média das máximas de $28,1^{\circ} \mathrm{C}$ e média das mínimas de $18,7^{\circ} \mathrm{C}$ (Dados obtidos na Estação Meteorológica da PESAGRO-Rio).

Foram avaliados dez novos genótipos (híbridos intraespecíficos) de capim-elefante (Pennisetum purpureum, Schum) obtidos pelo programa de melhoramento genético de forrageiras da EMBRAPA Gado de Leite (CNPGL 91-25-01, CNPGL 94-09-01, CNPGL 91-06-02, CNPGL 94-07-02,CNPGL 92-70-02,CNPGL 92-79-02, CNPGL 93-32-02, CNPGL94-49-06, CNPGL 92-94-01 e BAG 66) e os cultivares de capim-elefante Napier e Cameroon.

O delineamento experimental adotado foi o de blocos casualizados, com três repetições. A parcela experimental foi composta por quatro linhas de $3 \mathrm{~m}$ de comprimento, espaçadas 1 m entre si (parcelas de $4 \times 3$ ). A área útil colhida

Tabela 1 - Precipitação pluviométrica $(\mathrm{mm})$, temperaturas médias mensais, médias das máximas e mínimas $\left({ }^{\circ} \mathrm{C}\right)$ e umidade relativa do ar (\%) durante o período experimental

Table 1 - Average rainfall $(\mathrm{mm})$, monthly temperatures (low, mean and high $-{ }^{\circ} \mathrm{C}$ ) and air relative humidity (\%) during the experimental period

\begin{tabular}{|c|c|c|c|c|c|c|c|}
\hline \multirow[t]{2}{*}{$\begin{array}{l}\text { Mês } \\
\text { Month }\end{array}$} & \multirow[t]{2}{*}{$\begin{array}{c}\text { Precipitação }(\mathrm{mm}) \\
\text { Rainfall }\end{array}$} & \multicolumn{3}{|c|}{$\begin{array}{c}\text { Temperatura }\left({ }^{\circ} \mathrm{C}\right) \\
\text { Temperature }\end{array}$} & \multicolumn{3}{|c|}{$\begin{array}{l}\text { Umidade relativa (\%) } \\
\text { Air relative humidity }\end{array}$} \\
\hline & & Média & Mín. & Máx. & Média & Mín. & Máx. \\
\hline Mar./2005 (Mar./2005) & 159,7 & 25,4 & 21,8 & 31,2 & 82,6 & 51,9 & 99,6 \\
\hline Abr./2005 (Apr./2005) & 54,7 & 24,6 & 20,6 & 30,8 & 81,6 & 47,4 & 99,7 \\
\hline Mai./2005 (May/2005) & 94,6 & 22,5 & 18,6 & 28,0 & 82,0 & 49,9 & 99,4 \\
\hline Jun./2005 (Jun./2005) & 75,8 & 20,9 & 17,0 & 27,2 & 85,4 & 51,0 & 99,9 \\
\hline Jul./2005 (Jul./2005) & 57,5 & 19,6 & 15,5 & 25,1 & 82,8 & 51,0 & 99,8 \\
\hline Ago./2005 (Aug./2005) & 5,5 & 21,4 & 16,8 & 28,1 & 80,2 & 42,9 & 99,9 \\
\hline Set./2005 (Sep./2005) & 128,7 & 21,3 & 18,1 & 25,7 & 82,4 & 56,3 & 99,4 \\
\hline Out./2005 (Oct./2005) & 38,6 & 24,0 & 20,0 & 29,9 & 78,0 & 47,0 & 98,9 \\
\hline Nov./2005 (Nov./2005) & 219,1 & 22,7 & 19,6 & 27,2 & 83,8 & 57,8 & 99,2 \\
\hline
\end{tabular}


$\left(1 \mathrm{~m}^{2}\right)$ resultou de duas fileiras centrais depois de eliminado $1 \mathrm{~m}$ em cada extremidade.

Em 19/3/2005, realizou-se adubação para estabelecimento, efetuada sobre os sulcos de plantio, correspondendo a $100 \mathrm{~kg}$ de $\mathrm{P}_{2} \mathrm{O}_{5} / \mathrm{ha}$, na forma de superfosfato simples, e $25 \mathrm{~kg}$ de micronutrientes (FTE)/ha. Por ocasião do plantio, procedeu-se à irrigação durante as primeiras semanas de rebrota. Em 16/9/2005, sucedeu o corte de uniformização, seguido de adubação de cobertura com $100 \mathrm{~kg}$ de N/ha e $60 \mathrm{~kg}$ de $\mathrm{K}_{2} \mathrm{O} / \mathrm{ha}$.

A estimativa da produção de forragem na área útil foi obtida pelo corte a $30 \mathrm{~cm}$ do solo, aos 56 dias após o corte de uniformização. Na ocasião do corte, determinou-se a altura do estande, correspondente à distância entre o nível do solo e o nível médio da curvatura das lâminas das folhas superiores completamente expandidas. Retiraram-se uma amostra da área útil de cada parcela, aproximadamente $1 \mathrm{~kg}$, para determinação da relação folha/colmo (F/C), e outra amostra para análise dos teores de MS e PB e da digestibilidade in vitro da MS (DIVMS) da planta inteira.

O material relativo à relação folha/colmo foi separado em folha e colmo + bainha, pesado e colocado separadamente em sacos de papel, os quais foram encaminhados diretamente para estufa de circulação forçada a $55^{\circ} \mathrm{C}$ por 72 horas. Posteriormente, as amostras foram pesadas e processadas em moinho com peneiras de crivos de $1 \mathrm{~mm}$ e acondicionadas em recipiente hermeticamente fechado. O mesmo procedimento foi adotado para análises da planta inteira, porém, sem separação de colmo e folha. As análises dos teores de MS e PB foram realizadas segundo AOAC (1990). A DIVMS foi determinada segundo metodologia de Tilley \& Terry (1963), com período de incubação de 48 horas. O rendimento de MS foi calculado multiplicando-se a produção de matéria verde de cada repetição pelo seu respectivo teor de MS. A produção total de MS por genótipo resultou da média das repetições dos respectivos tratamentos. A produção de PB foi obtida multiplicando-se o teor de PB de cada repetição por sua respectiva produção de $\mathrm{MS}$ a $105^{\circ} \mathrm{C}$. A produção total de PB por genótipo resultou da média das repetições dos respectivos genótipos. A produção de MS digestível (MSD) foi determinada multiplicando-se a DIVMS de cada repetição por sua respectiva produção de MS a $105^{\circ} \mathrm{C}$. A produção total de MSD por tratamento resultou da média das repetições dos respectivos genótipos.

Os resultados referentes à altura da planta, à relação $\mathrm{F} / \mathrm{C}$ e às produções de $\mathrm{MS}, \mathrm{PB}$ e MSD foram submetidos à análise de variância pelo Sistema de Análises Estatísticas SISVAR (Ferreira, 1999) e ao teste Scott-Knott para verificar diferenças entre os genótipos. As variáveis foram analisadas de acordo com o modelo:

$$
\mathrm{Y}_{\mathrm{ijk}}=\mu+\mathrm{T}_{\mathrm{i}}+\mathrm{B}_{\mathrm{j}}+\mathrm{e}_{\mathrm{ijk}}
$$

em que $\mathrm{Y}_{\mathrm{ijk}}=$ resposta experimental medida sob o genótipo $\mathrm{i}$, na repetição $\mathrm{k}$ do bloco $\mathrm{j} ; \mu=$ efeito da média; $\mathrm{T}_{\mathrm{i}}=$ efeito relativo ao genótipo $\mathrm{i}, \mathrm{i}=1 ; 2 ; \ldots 12 ; \mathrm{B}_{\mathrm{j}}=$ efeito relativo ao bloco $\mathrm{j}, \mathrm{j}=1 ; 2 ; 3 ; \mathrm{e}_{\mathrm{ijk}}=$ erro aleatório.

A partir das médias obtidas realizou-se análise de agrupamento utilizando o procedimento Cluster (Bussab et al., 1990) no intuito de verificar a similaridade entre os genótipos de capim-elefante avaliados, considerados objetivos, e as variáveis avaliadas como interesse para critérios de parecença (similaridade), determinados pelo método das distâncias médias (MMD).

\section{Resultados e Discussão}

Houve diferença $(\mathrm{P}<0,05)$ entre os genótipos quanto à altura das plantas (Tabela 2). A altura das planta dos genótipos CNPGL 92-79-02, BAG 66 e Cameroon foram maiores em comparação às dos demais genótipos (Tabela 2) e apresentaram ainda maiores produções de MS. O genótipo CNPGL 91-25-01 apresentou menor altura em comparação aos demais (Tabela 2). De modo geral, estes dados estão de acordo com os descritos por Oliveira (1988) e Santos et al. (1994), que comprovaram que genótipos mais produtivos também apresentaram maiores alturas. O cultivar Cameroon apresentou 2,27 $\mathrm{m}$ de altura, enquanto o Napier apresentou $2,05 \mathrm{~m}$.

A relação folha/colmo não diferiu $(\mathrm{P}>0,05)$ entre os genótipos (Tabela 2), no entanto, os genótipos CNPGL 91-25-01 e CNPGL 94-09-01 se destacaram em valores absolutos. O fato de os genótipos não alcançarem melhores relações $\mathrm{F} / \mathrm{C}$, como no caso daqueles mais adaptados à região, como Napier e Cameroon, não compromete esta seleção, uma vez que a tendência é que a adaptação dos híbridos melhora com o passar do tempo. O genótipo CNPGL 91-25-01, que, em valores absolutos apresentou melhor relação $\mathrm{F} / \mathrm{C}$, apresentou também menor altura e produção (Tabela 2). Então, o crescimento desta planta foi menor e refletiu em menor alongamento do colmo, aumentando a proporção foliar. O genótipo CNPGL 94-09-01, além de apresentar relação próxima ao CNPGL 91-25-01, possibilitou ainda maior produção de MS. A relação F/C é importante na previsão do valor nutritivo de um cultivar, pois indica a proporção de caules presentes na forrageira. $\mathrm{O}$ valor nutritivo dos caules é menor que o das folhas, logo, alta proporção de folhas em relação a colmos constitui característica desejável à forrageira por estar diretamente relacionada à qualidade e ao consumo, principalmente em espécies forrageiras com colmos mais espessos, como o capim-elefante (Laredo \& Minson, 1973). Ressalta-se que a qualidade do colmo está relacionada à idade de rebrota da planta. 
Tabela 2 - Altura das plantas (m), relação folha/colmo (F/C na MS) e produções (t/ha) de MS, PB e matéria seca digestível (MSD) de genótipos de capim-elefante*

Table 2 - Plant height $(m)$, leaf/stem ratio (L/S on DM), DM, CP, and digestible DM (DDM) production (t/ha) of elephantgrass genotypes*

\begin{tabular}{|c|c|c|c|c|c|}
\hline $\begin{array}{l}\text { Genótipo } \\
\text { Genotype }\end{array}$ & $\begin{array}{l}\text { Altura }(\mathrm{m}) \\
\text { Height }(\mathrm{m})\end{array}$ & $\begin{array}{l}\mathrm{F} / \mathrm{C} \\
L / \mathrm{S}\end{array}$ & $\begin{array}{c}\text { MS (t/ha) } \\
D M(t / h a)\end{array}$ & $\begin{array}{c}\text { PB (kg/ha) } \\
C P(\mathrm{~kg} / \mathrm{ha})\end{array}$ & $\begin{array}{c}\text { MSD }(\mathrm{t} / \mathrm{ha}) \\
D D M(\mathrm{t} / \mathrm{h} a)\end{array}$ \\
\hline CNPGL 92-94-01 & $2,13 b$ & $1,35 \mathrm{a}$ & $12,90 \mathrm{a}$ & $1.284,20 \mathrm{a}$ & $7,69 a$ \\
\hline CNPGL 92-79-02 & $2,40 \mathrm{a}$ & $1,12 \mathrm{a}$ & $13,50 \mathrm{a}$ & $1.408,20 \mathrm{a}$ & $8,06 \mathrm{a}$ \\
\hline CNPGL 91-06-02 & $2,10 \mathrm{~b}$ & $1,07 \mathrm{a}$ & $12,60 \mathrm{a}$ & $1.311,50 \mathrm{a}$ & $7,53 \mathrm{a}$ \\
\hline Napier & $2,05 b$ & $0,95 \mathrm{a}$ & $9,20 \mathrm{~b}$ & $988,70 \mathrm{~b}$ & $5,16 \mathrm{~b}$ \\
\hline CNPGL 94-07-02 & $2,03 \mathrm{~b}$ & $1,23 \mathrm{a}$ & $12,90 \mathrm{a}$ & $1.415,70 \mathrm{a}$ & $7,72 \mathrm{a}$ \\
\hline CNPGL 91-25-01 & $1,78 \mathrm{c}$ & $1,43 \mathrm{a}$ & $7,30 \mathrm{~b}$ & $919,40 \mathrm{~b}$ & $4,67 b$ \\
\hline BAG 66 & $2,25 \mathrm{a}$ & $1,02 \mathrm{a}$ & $13,10 \mathrm{a}$ & $1.340,50 \mathrm{a}$ & $7,39 a$ \\
\hline CNPGL 93-32-02 & $2,13 b$ & $1,14 \mathrm{a}$ & $13,20 \mathrm{a}$ & $1.443,10 \mathrm{a}$ & $8,53 \mathrm{a}$ \\
\hline Cameroon & $2,27 \mathrm{a}$ & $1,27 \mathrm{a}$ & $14,50 \mathrm{a}$ & $1.591,00 \mathrm{a}$ & $8,70 \mathrm{a}$ \\
\hline $\mathrm{CV}(\%)$ & 5,50 & 22,47 & 21,90 & 21,19 & 24,13 \\
\hline
\end{tabular}

* Médias seguidas de mesma letra não diferem $(P>0,05)$ pelo teste Scott-Knott.

* Means followed by the same letter do not differ $(P>0.05)$ by Scott-Knott test.

Poli et al. (1994), caracterizando cultivares de capimelefante na estação experimental de Águas Belas, RS, também não verificaram diferenças $(\mathrm{P}>0,05)$ entre Cameroon e Napier para relação F/C na idade de 61 dias. Entretanto, ambos possibilitaram maiores valores para esta característica em comparação aos valores obtidos neste estudo (Tabela 2), 2,84 e 3,41, respectivamente. A maior relação obtida pode estar relacionada ao ambiente em que as plantas foram cultivadas, o qual promove crescimento mais lento. Queiroz Filho et al. (1998) avaliaram cultivares de capim-elefante no Brejo Paraibano, PB, durante aproximadamente dois anos e determinaram para cv. Cameroon valor de 1,15 para a relação $\mathrm{F} / \mathrm{C}$. O resultado obtido neste trabalho mostrou certa similaridade com o verificado anteriormente para o mesmo cultivar. O valor obtido neste estudo para relação folha/como (Tabela 2) foi inferior ao encontrado por Botrel et al. (2000), de 2,24 para cv. Cameroon no período das águas em Coronel Pacheco, MG. A menor altura da planta $(1,80 \mathrm{~m})$ aliada à maior altura de corte $(50 \mathrm{~cm})$ certamente colaborou para maior relação observada pelos autores.

As produções de MS diferiram entre os genótipos $(\mathrm{P}<0,05)$ e foram maiores para os genótipos CNPGL 92-94-01, CNPGL 92-79-02,CNPGL 91-06-02,CNPGL 94-07-02,CNPGL 94-09-01, BAG 66, CNPGL 93-32-02 e Cameroon (Tabela 2). A produção do cultivar Cameroon (14,52 t MS/ha) foi $63,22 \%$ maior que a do Napier $(9,18 \mathrm{t} \mathrm{MS} / \mathrm{ha})$. Botrel et al. (2000), avaliando genótipos de capim-elefante na Zona da Mata de Minas Gerais, encontraram para cv. Cameroon produções médias de MS (período das águas) de 24,2 t $\mathrm{MS} / \mathrm{ha}$, bem superiores à encontrada neste trabalho para o mesmo cultivar. A idade de corte da forrageira em questão, aliada ao período de avaliação, pode ter colaborado para a maior produção. Dall'agnol et al. (2004), avaliando o cultivar Cameroon na Estação Experimental de Lajes-SC, obtiveram aos 63 dias de crescimento 3,3 t MS/ha. Provavelmente a menor altura de corte $(1,2 \mathrm{~m})$ refletiu em menor produção de MS, uma vez que os autores determinaram valores bem maiores que os obtidos anteriormente com altura de 2,00 m. Pedreira \& Boin (1969), em Nova Odessa, SP, encontraram para cv. Napier produções de 2,7;12,8; e 14,9t/ha de MS aos 21,84 e 105 dias de crescimento da planta, respectivamente, provavelmente em virtude do maior intervalo de corte (Tabela2).

A produção de $\mathrm{PB}$ diferiu $(\mathrm{P}<0,05)$ entre os genótipos, de modo que os maiores valores foram obtidos com os genótipos CNPGL 92-94-01, CNPGL 92-79-02, CNPGL 91-06-02, CNPGL 94-07-02, CNPGL 94-09-01, BAG 66, CNPGL 93-32-02 e Cameroon (Tabela 2). Os cultivares Napier e Cameroon produziram 988,7 e 1591,0 kg/ha de PB, respectivamente, o que comprova a superioridade do cultivar Cameroon nas condições deste experimento.

Os resultados de MS digestível diferiram $(\mathrm{P}<0,05)$ entre os genótipos e, novamente, CNPGL 92-94-01, CNPGL 92-79-02,CNPGL91-06-02, CNPGL94-07-02,CNPGL94-09-01, BAG 66, CNPGL 93-32-02 e Cameroon apresentaram as maiores produções para este caráter. O cultivar Cameroon, em comparação ao Napier, destacou-se pela maior produção de MS digestível (Tabela 2). Os genótipos não diferiram quanto à DIVMS, mas apresentaram diferenças na produção de MS (Tabela 2) proporcionando divisão e formando grupos com maior e menor produção de MS digestível.

O resultado da análise de agrupamento foi apresentado na forma de dendrograma (Figura 1) considerando a 


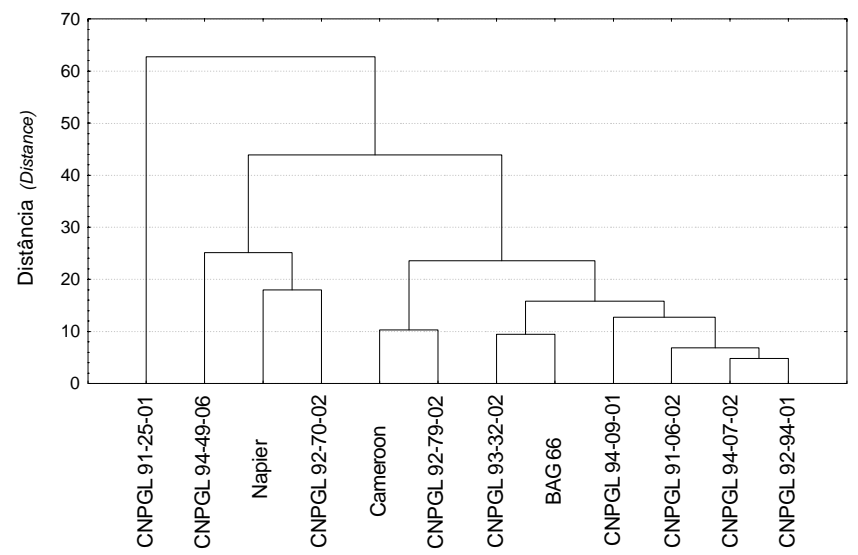

Tabela 3 - Perfil dos grupos de genótipos de capim-elefante formados pela análise de agrupamento de parâmetros relacionados à altura da planta $(m)$, à relação folha/colmo (F/C na MS) e às produções (t/ha) de MS, PB e MS digestível (MSD), referente à média dos constituintes de cada grupo

Table 3 - Elephantgrass genotypes distribution, according a group analyses, considering plant height (m), leaf/stem ratio (L/S on DM), DM, CP, and digestible DM (DDM) production (t/ha), considering an average of the constituents in each group

\begin{tabular}{|c|c|c|c|c|c|c|}
\hline $\begin{array}{l}\text { Grupo } \\
\text { Group }\end{array}$ & $\begin{array}{l}\text { Genótipo } \\
\text { Genotype }\end{array}$ & $\begin{array}{l}\text { Altura }(\mathrm{m}) \\
\text { Height }(\mathrm{m})\end{array}$ & $\begin{array}{l}\mathrm{F} / \mathrm{C} \\
L / S\end{array}$ & $\begin{array}{c}\mathrm{MS}(\mathrm{t} / \mathrm{ha}) \\
D M(t / h a)\end{array}$ & $\begin{array}{c}\text { PB }(\mathrm{kg} / \mathrm{ha}) \\
C P(\mathrm{~kg} / \mathrm{ha})\end{array}$ & $\begin{array}{c}\operatorname{MSD}(\mathrm{t} / \mathrm{ha}) \\
D D M(\mathrm{t} / \mathrm{h} a)\end{array}$ \\
\hline 1 & CNPGL 91-25-01 & 1,78 & 1,43 & 7,30 & 919,40 & 4,67 \\
\hline 2 & CNPGL 94-49-06 & 2,03 & 1,17 & 10,40 & 1103,90 & 6,02 \\
\hline 3 & CNPGL 92-70-02 e Napier & 2,06 & 1,14 & 8,85 & 979,95 & 4,72 \\
\hline 4 & Cameroon e CNPGL 92-79-02 & 2,33 & 1,19 & 14,00 & 1499,60 & 8,38 \\
\hline 5 & BAG $66 \mathrm{C}$ e NPGL 93-32-02 & 2,19 & 1,08 & 13,15 & 1391,80 & 7,96 \\
\hline 6 & CNPGL 94-09-01 & 2,08 & 1,40 & 13,10 & 1481,70 & 7,87 \\
\hline 7 & CNPGL 91-06-02 & 2,10 & 1,07 & 12,60 & 1311,50 & 7,53 \\
\hline 8 & CNPGL 94-07-02 e CNPGL 92-94-01 & 2,08 & 1,29 & 12,90 & 1349,95 & 7,70 \\
\hline
\end{tabular}

Método das distâncias médias (MMD) e dissimilaridade baseada na distância Euclideana de variáveis padronizadas. Average distance method (ADM), and dissimilarity, considering Euclidean distance of the standard variables.

CNPGL 92-94-01 e CNPGL 91-06-02 revelaram-se materiais superiores concomitantemente em produção de proteína bruta e de matéria seca digestível e podem ser considerados promissores para as condições da região norte-fluminense na estação da primavera. A análise de agrupamento sugeriu o fracionamento desses genótipos para cinco grupos, com destaque para o quarto conglomerado, representado pelo cultivar Cameroon e o genótipo CNPGL 92-79-02, que apresentaram as maiores produções de PB e MSD.

\section{Agradecimento}

À Universidade Estadual do Norte Fluminense, Campus Darcy Ribeiro, e ao Centro de Ciências e Tecnologias Agropecuárias, pela realização do experimento. altura Euclideana para formação de conglomerados. Logo, foram definidos oito conglomerados principais (Figura 1; Tabela 3).

Correlacionando este agrupamento aos dados médios das variáveis utilizadas (Tabela 3 ), pode-se propor, como principais interpretações, a existência de um grupo de genótipos com maiores produções de MS, representados

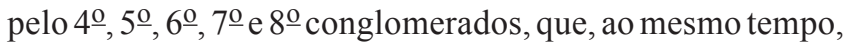
apresentaram maiores produções de $\mathrm{PB}$ e MSD. O genótipo CNPGL 91-25-01, de forma isolada, formou o primeiro conglomerado, em virtude das menores produções de MS, PB e MSD em relação às demais médias.

\section{Conclusões}

O cultivar Cameroon e os genótipos CNPGL 92-79-02, CNPGL93-32-02,BAG66,CNPGL94-09-01,CNPGL94-07-02, 
Anais... São Paulo: Associação Brasileira de Estatística, 1990. $105 \mathrm{p}$.

DALL'AGNOL, M.; SCHEFFER-BASSO, S.M.; NASCIMENTO, J.A.L. et al. Produção de forragem de capim-elefante sob clima frio. curva de crescimento e valor nutritivo. Revista Brasileira de Zootecnia, v.33, n.5, p.1110-1117, 2004.

EMPRESA BRASILEIRA DE PESQUISA E AGROPECUÁRIA EMBRAPA. Sistema brasileiro de classificação de solos. 2.ed. Rio de Janeiro: Embrapa Solos, 2006. 306p.

FERREIRA, D.F. Sistema de análise de variância SISVAR. Versão 4.0 (Build 34). Lavras: Universidade Federal de Lavras, 1999. (CD-ROM).

HANNA, W.W. Elephantgrass improvement. In: SIMPÓSIO SOBRE CAPIM-ELEFANTE, 1994, Juiz de Fora. Anais... Juiz de Fora: EMBRAPA-CNPGL, 1994. v.2, p.72-81.

LAREDO, M.A.; MINSON, D.J. The voluntary intake, digestibility and retention time by sheep leaf and stem fractions of five grasses. Australian Journal of Agricultural Research, v.24 p.875-888, 1973.

OLIVEIRA, J.A.C. Potencial forrageiro de clones de capimelefante (Pennisetum purpureum, Schum) e de capimelefante $x$ milheto (Pennisetum americanum (L) Leeke) no agreste semi-árido de Pernambuco. Recife: Universidade Federal Rural de Pernambuco, 1988. 233p. Dissertação (Mestrado em Produção Animal) - Universidade Federal Rural de Pernambuco, 1988.

OMETTO, J.C. Bioclimatologia vegetal. São Paulo: Agronômica Ceres Ltda., 1981. 440p.
PEDREIRA, J.V.S.; BOIN, C. Estudo do crescimento do capimelefante variedade Napier (Pennisetum purpureum Shum.). Boletim Indústria Animal, v.26, p.263-273, 1969.

POLI, C.H.E.C.; JACQUES, A.V.A.; CASTILHOS, Z.M.S.C. et al. Caracterização morfológica de cinco cultivares de capimelefante. Revista da Sociedade Brasileira de Zootecnia, v.23, n.2, p.205-210, 1994.

QUEIROZ FILHO, J.L.; SILVA, D.S.; NASCIMENTO, I.S. et al. Produção de matéria seca e qualidade de cultivares de capimelefante (Pennisetum purpureum, Schum). Revista Brasileira de Zootecnia, v.27, n.2, p.262-266, 1998.

SANTOS, M.C.M.; TABOSA, J.N.; DIAS, F.M. et al. Comportamento de clones de capim-elefante e de híbridos de capim-elefante $\mathrm{x}$ milheto no Semi-Árido do Nordeste do Brasil. Pesquisa Agropecuária Brasileira, v.29, n.10, p.1609-1615, 1994.

TILLEY, J.M.A.; TERRY, R.A. A two-stage technique for the "in vitro" digestion of forage crops. Journal British Grassland Society, v.18, n.2, p.104-111, 1963. 